\title{
Recognition and naming of object-drawings by men with focal brain wounds
}

\author{
FREDA NEWCOMBE, R. C. OLDFIELD, G. G. RATCLIFF, AND A. WINGFIELD \\ From the Department of Neurology, Churchill Hospital, Oxford; M.R.C. Speech and Communication Unit, \\ University of Edinburgh; and Department of Psychology, Brandeis University, U.S.A.
}

SUMMARY The ability to name object-drawings, measured by score and response latency, was examined in men with chronic, focal brain lesions due to missile injury. The group with left hemisphere lesions was significantly impaired on both measures and this impairment was clearly related to the incidence of clinically detectable dysphasia. In contrast, the impairment of the bilateral group was not closely associated with dysphasia; it was characterized by long response latencies which exceeded the sum of unilateral deficits in the task. Analysis of response errors showed that both misnaming and misidentification occurred but were often dissociated. Difficulty in naming was noted in men with lesions involving the left temporal lobe. Misidentification was not common; it occurred more frequently in the bilateral group, in men with lesions of the occipital areas of the brain. Dissociated deficits were also noted within the group of men with residual dysphasia.

The peculiar difficulty which aphasic patients experience when asked to name objects has been known and used in clinical testing, almost from the time when disorders of speech resulting from cerebral lesions were first recognized as clinical entities. Broadbent (1884) reported it as a salient feature of the language breakdown in a patient with cerebrovascular disease predominantly affecting the territory of the middle cerebral artery; and several authors, including Kinnier Wilson (1926), Symonds (1953), and Brain (1961) have noted its special association with temporal-lobe disorder. Among groups of neurological patients with dysphasia, the symptom may be related to the size of the lesion and the extent of temporal-lobe involvement (Hécaen and Angelergues, 1965).

In residual asphasia after trauma naming difficulties are often less severe. Nevertheless, Marie and Foix (1917), in their study of veterans of the first world war, commented that this symptom had persisted as the most characteristic feature some months after injury. Thirty years later, Schiller (1947) also noted the prevalence of residual naming difficulties in a group of dysphasic ex-servicemen. He did not, however, find any connection between the symptom and the presumed site of the lesion, concluding that 'this essential feature is the least valuable for localization'.
Symptoms of language impairment may nevertheless be relatively dissociated in traumatic aphasia. According to Alajouanine, Castaigne, Lhermitte, Escourolle, and Ribaucourt (1957), their case Blan (no. 29) showed a surprisingly persistent failure to name objects, although repetition, reading, and comprehension were intact, whereas their case Gom (no. 28) showed no such difficulties despite a cluster of symptoms including total alexia and agraphia.

The clinical literature of aphasia, although full of references to difficulties in naming, contains remarkably little quantitative work; and very few studies of response latency in object-naming have hitherto been reported. A pioneer in this field was Lotmar (1919) who published figures for a single patient. He noted in an aphasic patient a 'partially raised lengthening of the reaction time' but complete failure 'only as an exception' in naming object-pictures. Inspection of the latencies of Lotmar's dysphasic patient shows a relationship between latency and word frequency. This relationship was also implied, although never made explicit, by the work of Weisenburg and McBride (1935) who pointed out that mild disturbances in naming could be detected only by a slight hesitancy in the patient's responses, and to elicit these residual symptoms they had recourse to less familiar objects. This association between response availability and frequency of word usage 
was subsequently confirmed in clinical and experimental investigations (Wepman et al, 1956; Howes, 1964; Rochford and Williams, 1965).

In a preliminary report (Newcombe, Oldfield, and Wingfield, 1965) we also demonstrated an association between response latency and word frequency in the performance both of groups of men with unilateral cerebral lesions due to missile injury and of control subjects; a linear relationship was found between mean latencies for the naming of 26 object-drawings and the logarithm of the word frequency of the object-name. Men with residual dysphasic symptoms showed marked difficulty in naming objects with a frequency of occurrence of less than one in a hundred thousand according to the Thorndike and Lorge (1944) word list and both experimental groups had longer latencies than the control group. The present study includes those experimental groups and additional subjects including men with bilateral lesions. While reporting a further analysis of latency effects, our main concern here is with success or failure in naming and with the nature of errors. We also consider the clinical and anatomical features of those individual subjects who were significantly impaired in the task.

\section{METHOD}

SƯBJECTS The experimental subjects were drawn from a sample of men who incurred missile injury to the brain during the second world war and who participated in a follow-up examination between 20 and 25 years later. The background of this investigation has been described elsewhere (Newcombe, 1969). These injuries occurring in the normal young-adult brain often produce focal and very circumscribed deficits (Russell and Espir, 1961; Russell and Young, 1969). There were 125 experimental subjects, most of whom were fit and gainfully employed when the present investigation took place: 57 men had left hemisphere lesions and will be described as the LH group, 34 had right hemisphere lesions-the RH group, and 34 had bilateral lesions. All the subjects were righthanded.

There were two control groups. Control group I consisted of 25 men who were attending the same hospital as the experimental subjects, to undergo minor surgery. There was no history of brain damage among these subjects and they did not differ as a group in age or vocabulary level from the experimental groups (see Table 1). Control group II consisted of $25 \mathrm{men}$, also in the same age group, admitted for minor surgery to a hospital in another part of Great Britain.

MATERIAL The material consisted of 36 simple outline drawings of objects-each on a card $15 \times 10 \mathrm{~cm}$-the first 10 of which were for practice. This material had been used in previous studies (Oldfield and Wingfield, 1965a), and included objects whose names occurred throughout
TABLE 1

AGE AND VOCABULARY IQ OF CONTROL AND EXPERIMENTAL $\underset{\mathbb{D}}{Z}$ GROUPS

\begin{tabular}{|c|c|c|c|c|c|}
\hline \multirow[t]{2}{*}{ Group } & \multirow[t]{2}{*}{$N$} & \multicolumn{2}{|c|}{ Age } & \multicolumn{2}{|c|}{ Vocabulary $I Q$} \\
\hline & & mean & $S D$ & mean & $S D$ \\
\hline Control I & 25 & $43 \cdot 0$ & $7 \cdot 6$ & $102 \cdot 8$ & $11 \cdot 4$ \\
\hline $\mathbf{R H}$ & 34 & $47 \cdot 3$ & 4.9 & $103 \cdot 1$ & $12 \cdot 2$ \\
\hline LH & 57 & $46 \cdot 2$ & $6 \cdot 2$ & $99 \cdot 1$ & 14.0 \\
\hline (dysphasic) & (29) & $(46.9)$ & $(6 \cdot 1)$ & $(95 \cdot 2)$ & $(14 \cdot 6)$ \\
\hline (non-dysphasic) & (28) & $(45 \cdot 4)$ & $(6 \cdot 1)$ & $(103 \cdot 1)$ & $(12 \cdot 1)$ \\
\hline Bilateral & 34 & $47 \cdot 5$ & 6.0 & 97.4 & 16.0 \\
\hline
\end{tabular}

a wide range on the Thorndike and Lorge (1944) frequency $\frac{}{5}$ count (from more than 100 occurrences per million words $\overline{\bar{c}}$. of text down to 1 per 3 million). Examples of these $\widehat{\Phi}$ drawings are shown in Fig. 1. A full list of them, together with the latencies and percentages of correct responses found for university subjects and for a hospital control $\overrightarrow{0}$ group, is given in Oldfield and Wingfield (1965b). Three different random orders for both the practice and the $\vec{\omega}$ test series were drawn up, and these orders of presentation were used alternately.

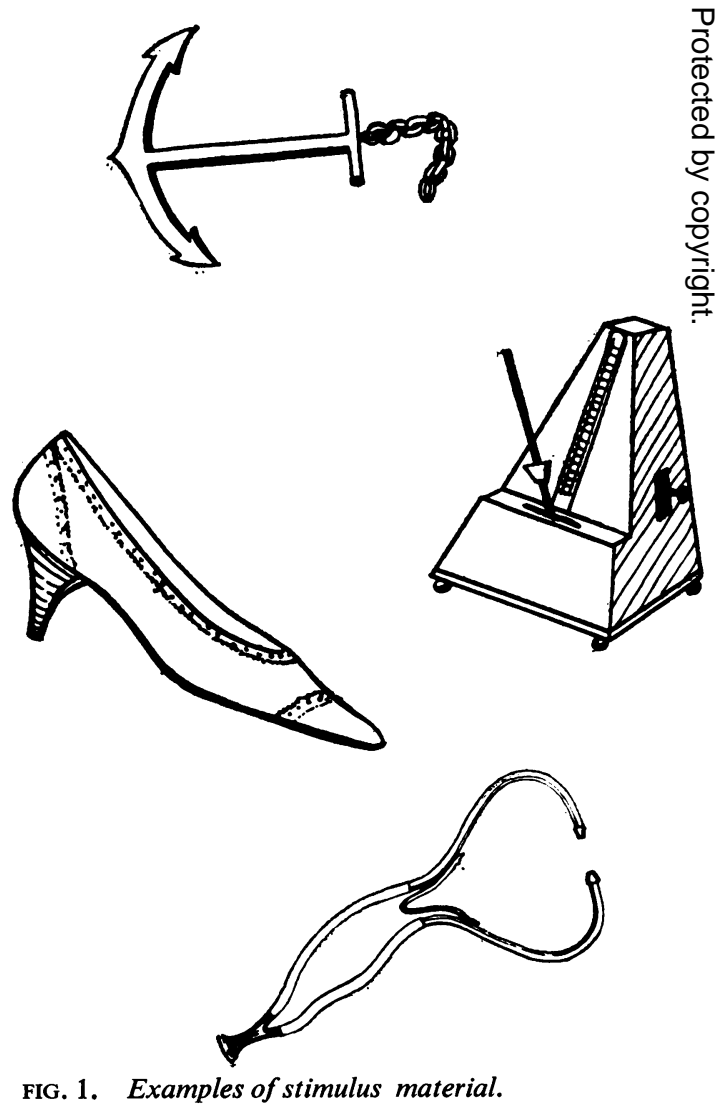

FIG. 1. Examples of stimulus material. 
PROCEDURE In the original experiment, on normal university subjects, the pictures were displayed by optical projection and the latency recorded by a voice key which operated a marker pen on an ink oscillograph. This procedure was simplified for the present experiment. Subject and experimenter sat opposite one another with a low screen on a table between them. The subject was told that he would see a series of cards and that each card had on it a drawing of an object. He was to name the object as quickly as he could, giving its common name without qualification or further description. To illustrate the instruction, he was given three examples of the naming of common objects in the room ('bag' 'window', and 'door'). He was then told that a signal 'Ready' would be given before each card was raised from behind the screen, and he was again reminded to respond as quickly as he could.

A 1/100 second stop watch was used to measure response latencies. Results for the first 10 practice cards were disregarded, though subjects were unaware of this. One point was given for each correct response, with a maximum score of 26 .

\section{RESULTS}

We may consider the data from three aspects: the performance of the experimental groups measured by either score or response-latency, the different sources of failure, and the characteristics of individual subjects whose response pattern was anomalous.

PERFORMANCE I-SUCCESS OR FAILURE The distribution of scores for the experimental and combined control groups is shown in Fig. 2. The median score of the control group was 24 and accordingly was used as a cut-off point to classify group distributions. On this basis the $\mathrm{LH}$ group was found to be significantly impaired in relation to control groups I and II $\left(\chi^{2}=3.90 \mathrm{P}<0.05\right)$ and the RH group $\left(\chi^{2}=11.10 \mathrm{P}<0.001\right)$. The bilateral group was significantly less efficient than the RH group $\left(\chi^{2}=8.54 \mathrm{P}<0.01\right)$ but no worse than the LH group $\left(\chi^{2}=0 \cdot 06\right)$.

The clear-cut relationship between score and dysphasia (diagnosed in clinical interview) in the unilateral LH group is illustrated in Fig. 3. The 29 men who are to be described as permanently dysphasic - that is, their dysphasia was still observed 20 years after injury-obtained scores ranging from 16 to 26 . The 12 men who were dysphasic on discharge from hospital after treatment of the head injury but who were not diagnosed as dysphasic at this follow-up examination (the early dysphasic group), obtained scores ranging from 22 to 26; and the group of 16 men who were not diagnosed as dysphasic, either during the acute phase or later, had scores ranging from 21 to 26 . The latter two groups were significantly more efficient than the group of subjects with permanent dysphasia $\left(\chi^{2}=9.93, \mathrm{P}<0.01\right)$, and their performance resembled that of control groups I and II or the RH group.
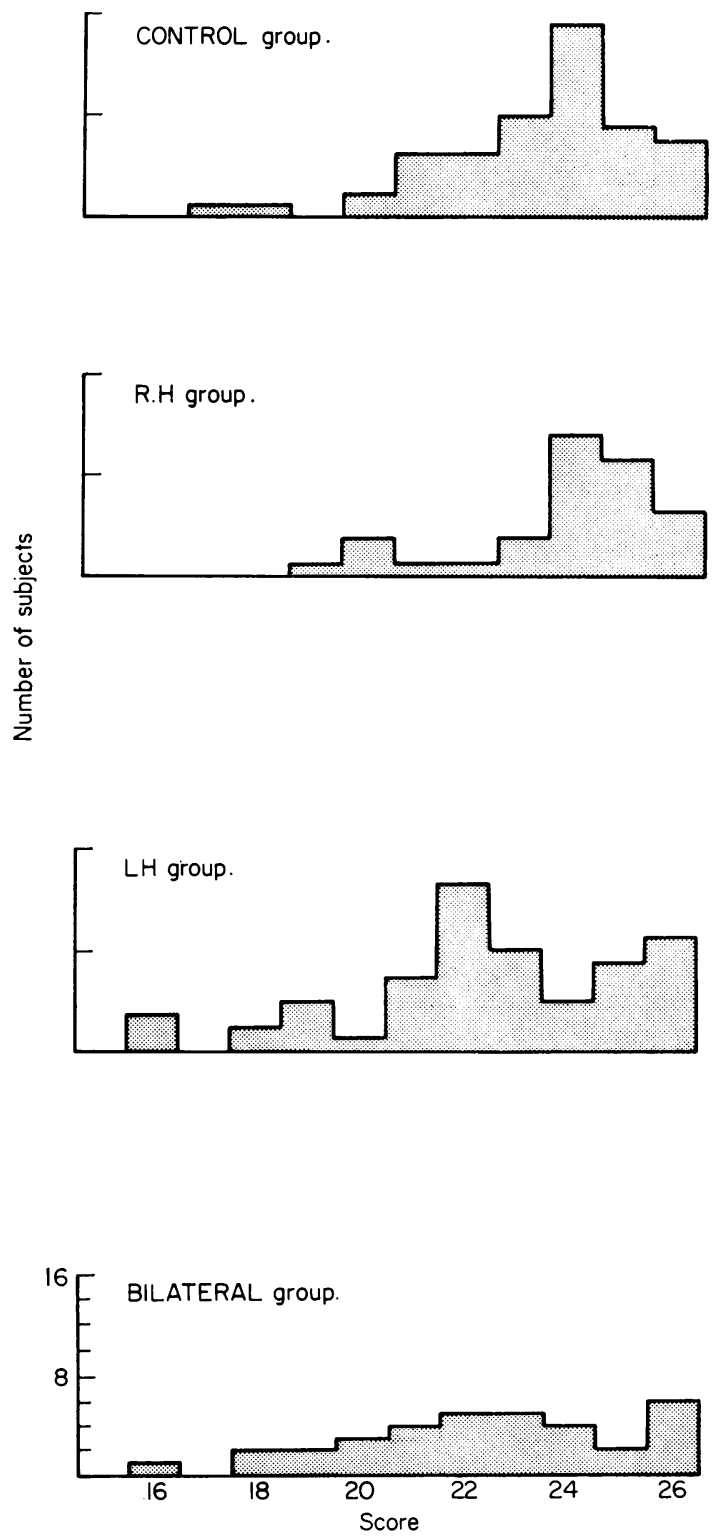

FIG. 2. Distribution of scores for experimental and control groups. 

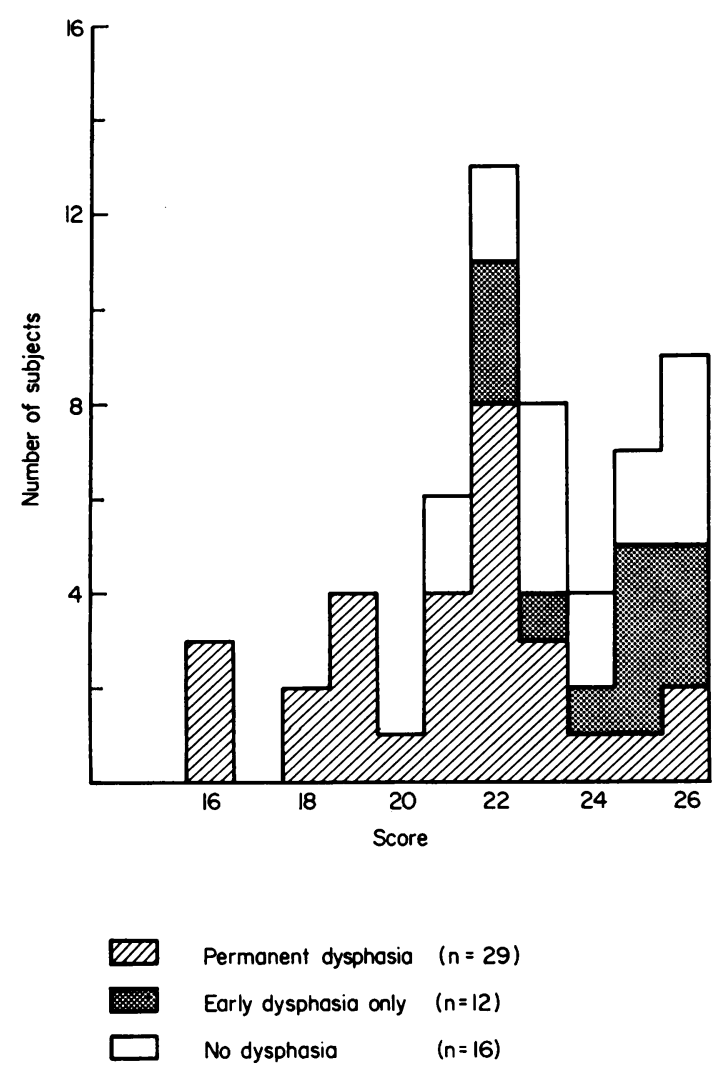

FIG. 3. Scores of subjects in the LH group, classified according to the incidence of dysphasia.

In contrast, the relationship between dysphasia and score was not clear-cut in the bilateral group. Eighteen of the group of 34 men with bilateral lesions had never been diagnosed as dysphasic but their performance was no better than that of the dysphasic subjects in this group.

PERFORMANCE II-RESPONSE LATENCY The present analysis of response latency was restricted to subjects who correctly named all objects in five of the seven frequency categories, thus including 20 objects, the names of which occurred within a frequency range of $1-100+$ per million words. This constraint allowed us to compare the performance of stable groups-29 men in the LH group, 24 in the RH group, 18 in the bilateral group, and 19 in control group I; and it excluded comparisons at the two lowest frequency ranges (0-0.9 per million), which inevitably have to be based on very small groups. ${ }^{1}$ All correct response latencies were included, whether or not they were preceded by other utter- $Z$ ances. As far as control data were concerned, we $\stackrel{\mathbb{D}}{=}$ considered the latencies of control group I only, since these men and the 125 experimental subjects were all tested by the same examiner (FN).

Mean response latencies plotted against word frequency are shown in Fig. 4. At all five frequency $\stackrel{\bigcirc}{S}$ levels the experimental groups (LH, RH, and bilateral) were significantly slower than control $\underset{\gtrless}{*}$ group I at probability levels below 0.01 on two-tailed Mann-Whitney tests-with only one exception. $\stackrel{5}{+}$ The difference in latency between the LH group and $\bar{C}$ control group I at the frequency range 1-9 per흘 million failed to reach statistical significance; but $\frac{\bar{N}}{\widehat{D}}$

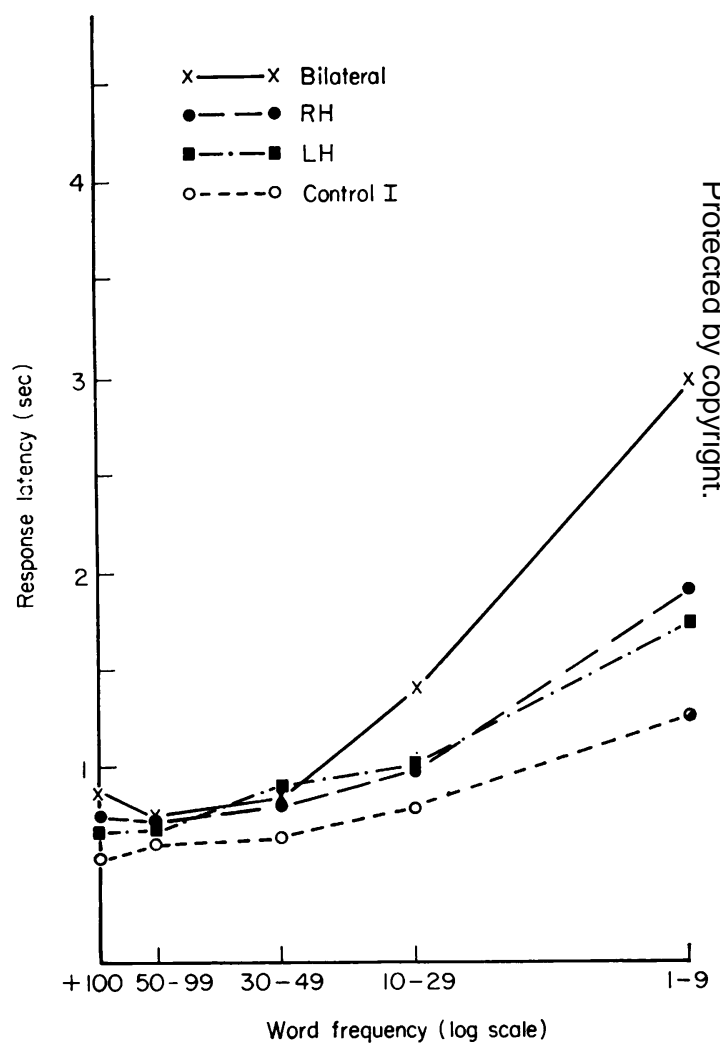

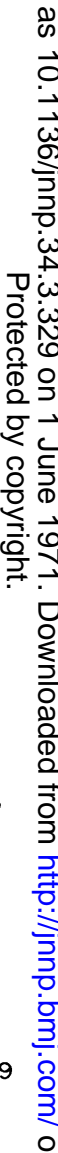

FIG. 4. Mean response latencies plotted against word frequency.

In our previous study of latency (Newcombe et al, 1965) we included at each frequency category, any subject who gave at least one response $\mathbb{N}$ and thus numbers in groups varied according to the frequency range. 
it should be noted that $51 \%$ of the $\mathrm{LH}$ group were already excluded from these comparisons by failure to name all 20 items, whereas only $25 \%$ of control group I were so excluded.

SOURCES OF FAILURE Errors were classified according to whether the stimulus picture was misnamed, misidentified, or 'not known'. The naming errors were usually unequivocal: the subject would describe or mime the function of the object (SYRINGE $\rightarrow$ 'a thing for pushing medicine... injector': XYLOPHONE $\rightarrow$ 'it's an awkward name, isn't it ... got an $X$ in it ... Teddy Brown used to play it'). Misidentification error was scored if the subject described the drawing as another object. (MICROSCOPE $\rightarrow$ 'drill': STETHOSCOPE $\rightarrow$ 'forceps . . or a violin'). When the subject declared that he did not know what the object was the error was scored as 'not known'.

The percentage distribution of the three types of error in the experimental groups and control group I is shown in Table 2, and the number of misidentifications made by individual subjects in Table 3 .

The proportion of subjects in the bilateral group who made one or more errors of misidentification was significantly higher than that of subjects making these errors in the unilateral groups $\left(\chi^{2}=5.42\right.$, $P<0.05)$ or in the control group I $\left(\chi^{2}=6.90\right.$, $P<0.01$ ).

The relationship between error type and stimulus picture proved to be similar for control and experimental groups (see Tables $4 a$ and $4 b$ ). Rank order correlations for the overall difficulty of the nine most difficult items were calculated for all group comparisons and were in all cases high and significantly positive. Naming errors were significantly related to low frequency words. Misidentification errors also tended to cluster at the low frequency end of the range which included objects that were less familiar and perhaps more complex visually.

TABLE 2

MEAN ERRORS AND PATTERN OF ERRORS IN CONTROL AND EXPERIMENTAL GROUPS

\begin{tabular}{lccc}
\hline \multirow{2}{*}{ Group } & \multicolumn{3}{c}{ Distribution of errors } \\
\cline { 2 - 4 } & $\begin{array}{c}\text { Misnaming } \\
(\%)\end{array}$ & $\begin{array}{c}\text { Misidentification } \\
(\%)\end{array}$ & $\begin{array}{c}\text { Not known } \\
(\%)\end{array}$ \\
\hline Control I & $51 \cdot 1$ & 8.5 & 40.4 \\
RH & 63.5 & 16.2 & 20.3 \\
LH & 71.6 & 11.4 & 16.9 \\
Bilateral & 56.6 & 25.4 & 18.0 \\
\hline
\end{tabular}

TABLE 3

INCIDENCE OF MISIDENTIFICATION BY SUBJECTS IN CONTROL AND EXPERIMENTAL GROUPS

\begin{tabular}{llrrrrr}
\hline \multirow{2}{*}{ Group } & $N$ & \multicolumn{5}{c}{ Number of misidentifications } \\
\cline { 3 - 6 } & & 0 & 1 & 2 & 3 & 4 \\
\hline Control I & $(25)$ & 21 & 4 & 0 & 0 & 0 \\
RH & $(34)$ & 26 & 6 & 1 & 0 & 1 \\
LH & $(57)$ & 39 & 13 & 5 & 0 & 0 \\
Bilateral & $(34)$ & 16 & 10 & 4 & 3 & 1 \\
\hline
\end{tabular}

INDIVIDUAL DEFICITS The distribution of scores in control groups I and II showed that a score of less than 20 was significantly low. Such a score was therefore considered to indicate deficit. Only two men among 50 normal control subjects and one man in the RH group had scores of less than 20 , whereas nine of the 57 men in the LH group and five of the 34 men in the bilateral group had such low scores. The nine men in the $\mathrm{LH}$ group were unequivocally dysphasic and four of them had global dysphasia. Their scores were well below the average in tests of vocabulary, arithmetic, and story recall; all except two were poor readers and one was frankly dyslexic, although five men could write adequately; but there was no suggestion of nonverbal intellectual deficit from their performance in standard tasks such as the Progressive Matrices and the Wechsler Block Design test. The clinical and anatomical features of these nine men (group A) together with tracings of the lateral and anteriorposterior radiographs are shown in Fig. 5a. Their lesions involved the region of the Sylvian fissure and the temporal lobe.

Of the five subjects with significantly low scores in the bilateral group, two were noted to have fairly severe global dysphasia during their recent admission: they were impaired in reading, writing, rote speech, fluency, and verbal memory and learning. The other three men have never been considered dysphasic: two of them had bifrontal injuries and one had never been literate.

Failure in the impaired subjects was mainly attributable to misnaming, although four of the five subjects in the bilateral group also made errors of misidentification. On the whole, misnaming and misidentification errors could be dissociated: there were subjects who misnamed but did not misidentify, and vice versa. Misidentification errors were rare in control group I: only four subjects made such an error and no subjects made more than one. Conversely, five men in the experimental groups made 


\section{FIG. 5a. Group A (marked naming difficulties) (key on opposite page).}

Case no. 6 He was wounded in 1944 at the age of 19. A bullet penetrated the brain in the region of the left ear and emerged from the high parietal region. The wound was debrided 13 hours after injury when numerous bone fragments were removed. This injury left him with a right homonymous hemianopia more pronounced in the right upper quadrant, a right spastic hemiparesis, and a depression of sensation down the whole of the right side. He developed epilepsy which is now well controlled. A month after wounding he was unable to speak but had two kinds of grunts to express 'yes' or 'no'. He could handle objects correctly - for example, comb or shaving brush-but failed to write more than his name in print. Severe reading and writing difficulties have persisted but he has regained enough speech to make his meaning clear, although it is halting and telegrammatic in style. He has been classified as unemployable and lives in an institution for disabled servicemen.

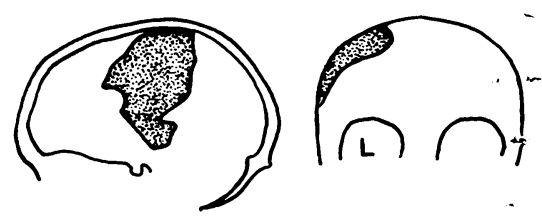

Case no. 116 He was wounded in 1944 at the age of 24 , by a missile which entered the skin $3 \frac{1}{2} \mathrm{~cm}$ behind the left external auditory meatus and emerged at the lateral side of the left orbit. The floor and lateral aspect of the middle fossa were severely shattered and the inner ear, mastoid, and facial nerve were destroyed. Many bone fragments were removed during operation three days after injury. He had a permanent right homonymous superior quadrantanopia, complete left facial paralysis, and deafness on the left side. Four days after injury he was able to ask for a drink and could follow simple instructions, although he had difficulty in expressing himself and failed to name several common objects. A month after injury he was speaking better and comprehension had improved, but he still showed a marked nominal dysphasia. Difficulties in reading and writing have persisted. He was able to do full-time factory work until 1965 , since when he has been under treatment for diabetes and hypertension. In 1967 he suffered an acute myocardial infarction and has subsequently been unfit to work.

Case no. 184 He was wounded in 1944 at the age of 30, by a missile which penetrated the brain in the left parieto-temporal region. On examination he was conscious but markedly dysphasic; comprehension was defective and he spoke jargon. During operation, 42 hours after wounding, about 20 bone chips were removed from the brain. He had transient motor weakness, more marked in the arm than in the leg, and permanent sensory loss (impairment of two-point discrimination and appreciation of passive movement). A transient right homonymous hemianopia cleared and he has subsequently showed full visual fields on perimetry. He developed post-traumatic epilepsy but for six months before his recent admission in 1969 had been free of seizures. A week after injury he could say little but 'yes', 'please', and 'no'; and he could not read or name letters. Two weeks after injury he was speaking better and his comprehension, although poor, had improved. A month after injury he still showed a marked nominal dysphasia. He failed to name such common objects as cigarette and basket and made many paraphasic errors in naming other objects but knew when he had made a mistake. He was able to read fluently but still had a marked comprehension defect. In the following two years there was a considerable improvement in spelling and calculation but a slight comprehension defect could still be detected, although his spontaneous speech was considered to be normal. He has been able to work full-time in a small branch post office but has not been in charge as he was before his injury.

Case no. 368 He was injured in 1944 at the age of 24. Metal fragments penetrated the upper part of the left temporal lobe and passed right into the mid-brain to destroy the third cranial nerve. At operation the same day, bone fragments were removed from the track. Subsequently, the right visual fields were full and sensory-motor functions were unimpaired. Four days later he could understand and obey simple commands but lapsed into jargon when questioned and gave unintelligible names for objects followed by an appropriate gesture to illustrate their use. A few months after injury the signs of language disturbance were minimal. He has worked regularly since injury and now runs a small shop.

Case no. 417 In 1944, at the age of 18, this man incurred a through-and-through wound of the left frontotemporal region which also destroyed the left orbit. At operation the following day bone fragments and lacerated brain were removed in an area extending from the falx to the base of the temporal fossa. The injury led to a permanent sector defect in the remaining right upper quadrant but no impairment of sensorymotor function. Three months after injury he showed nominal difficulties and had difficulty in reading and writing, but before wounding he had never been fully literate. He worked as a gardener before the war and thereafter tried factory work but found it noisy and tiring. For the past 11 years he has worked full-time as a carpenter.

Case no. 580 He was wounded in 1945 at the age of 30 and the initial debridement was carried out in a civilian unit abroad. He was then evacuated to the United Kingdom. At this time he was conscious, aphasic, and had a right hemianopia and a right hemiplegia. Five days after injury he had a second operation during which bone fragments and lacerated brain were removed and a temporal lobe abscess evacuated. No permanent visual field defect resulted, but the injury left impairment of light touch, pinprick, proprioception and vibration sense in the right hand. Also, there was a slight loss of the ability to perform fine movements with the right hand. He developed epilepsy and still has nocturnal attacks beginning with tremor of the right hand and becoming generalized; these now occur approximately once every six weeks. He had been unable to speak at all during the acute post-traumatic period and had difficulty in understanding speech. Language functions improved very slowly over the years but his spontaneous speech is still markedly impaired and he has difficulty in understanding fast speech. He now reads slowly but has to reread the text to understand it. He can write letters but his wife corrects them. Formerly the manager of an engineering shop, he has not worked full-time since his injury, but uses a knitting machine at home.

Case no. 808 He was wounded in 1945 at the age of 20 by a bullet which was embedded in left temporal muscle; it was removed at operation 26 hours later when an extradural clot was also removed from the floor and lateral wall of the temporal fossa. The injury caused permanent damage to the left eye, the residual vision consisting of an arc in the lower quadrants extending across, whereas the visual field of the right eye has been full. Within a year of injury he had several attacks of psychomotor epilepsy and at least one major seizure, but he has not had any fits of recent years. During the acute phase he had nominal difficulties; he also made errors in reading and writing, and his speech was hesitant. He himself noted difficulty in following wireless news, film, rapid speech, or conversation with three or four people at the same time. On discharge he attended agricultural courses but found it difficult to learn. Ten years after injury he reported good health but 'great difficulty in remembering and in being able to think of what to say when other people talk to me'. With remarkable persistence he finally qualified as a land agent and now works full-time.
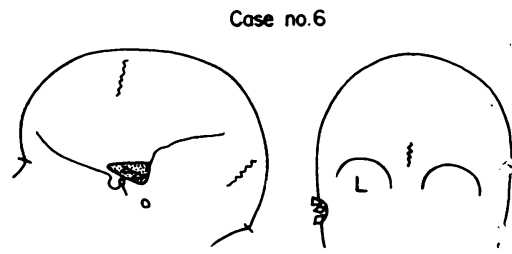

Cose no. 116
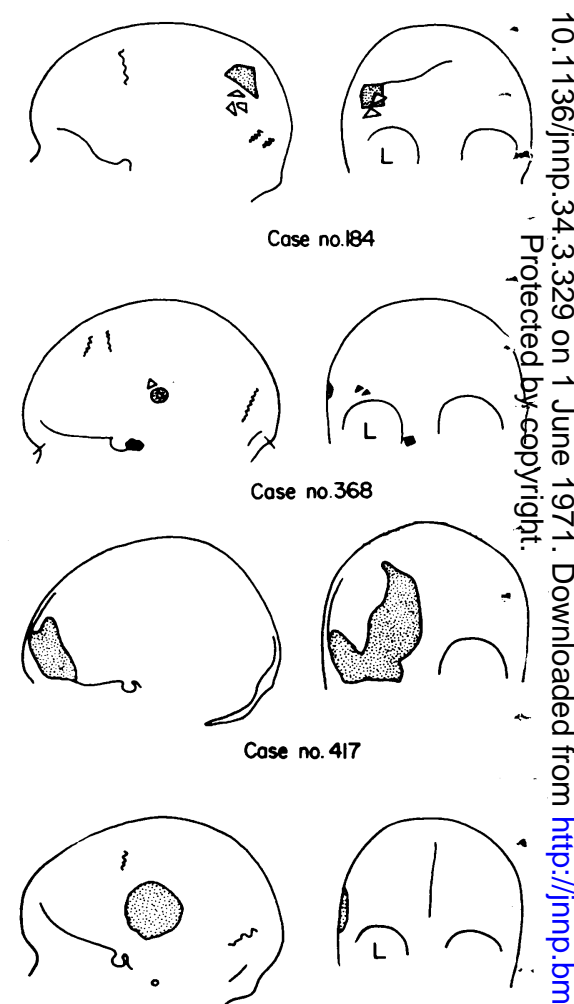

$$
\text { Cose no. } 580
$$

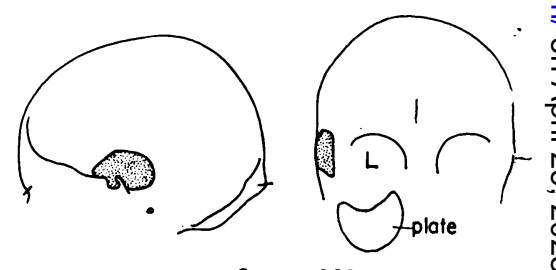

Cose no. 808 
Case no. 889 He was wounded in 1945 at the age of 29 by a mortar bomb fragment and was operated on some 36 hours after injury. Half a dozen large bone chips were removed from a track which passed down- wards and medially from the left fronto-parietal bone defect for about 6 to $8 \mathrm{~cm}$. The injury left him with - a $:$ vere permanent right hemiparesis, slight right-sided cortical sensory loss affecting the arm more than the face and leg, but no visual field defect. He had a few generalized fits in the year after the injury but none subsequently. A week after the operation he was able to understand a few simple commands but could not speak at all. During the next five years there was a slow but definite improvement in spontaneous speech. During the recent admission in 1969 he showed marked word-finding and dysarthric difficulties. - He had joined the Army as a regular soldier but has not been employed since his injury.

Case no. 896 This man was wounded in 1941 at the age of 27 , by a piece of shrapnel. The wound was - debrided the same day but no foreign bodies were located. Radiographic examination a month later revealed a bony defect $1 \times 1.5 \mathrm{~cm}$ in the left fronto-parietal region. Three 'fair-sized' and 'about a half lozen -sm.al! bony fragments' together with a small metal fragment were indriven from this bony defect, the deepest lying about $2 \mathrm{~cm}$ downwards and inwards. A larger piece of metal had passed directly downwards and was lying $1 \mathrm{~cm}$ above and to the left of the left anterior clinoid process. He developed epilepsy, preceded by an aura in which 'I think of lots of numbers and letters and I find I cannot speak'. He now has blackouts several times a month, during which he is aware of his surroundings but cannot talk for half an hour. A month after injury he was reported to show 'a certain amount of nominal dysphasia-for example, calls an orange a banana'. A month later, however, speech was fluent, he could read and write without difficulty, and he understood words, commands, and stories both in spoken and in written language. Some 20 years iuter the subject himself reported that he seldom reads because he is unable to recall content. Before the war he worked in an agricultural business; he now runs a small hotel.

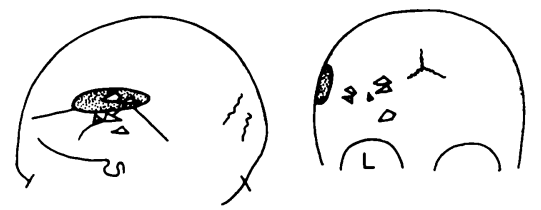

Cose no. 889

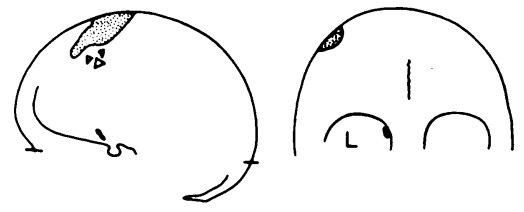

Cose no. 896

FIG. 5b. Group B (high incidence of misidentification).

Cúse no. 72 He was wounded in 1944 at the age of 24 when a spent bullet lodged itself in the right occipital region causing a complete left homonymous hemianopia which has persisted. At operation two days efter wounding the bullet and bone chips were removed from the area of the bony defect which was $6 \times 4$ $\mathrm{cm}$. Five days after the operation he was sitting up and talking sensibly, but could not read print; this difficulty soon cleared. At no time were any dysphasic features noted. He developed epilepsy during the acul: phase but there has been no report of fits in the succeeding two decades. He works as a car park attendant.

Case no. $152 \mathrm{He}$ was wounded in 1944 at the age of 23 , by a missile which penetrated the brain in the occipital region to the right of the midline, $3.7 \mathrm{~cm}$ from the inion. This at first caused total blindness but visual acuity later returned to normal (6/5). There were, however, dense paracentral scotomata which are still much the same as they were when recorded in 1945. At operation, two days after injury, depressed hone fragments were removed leaving a residual bone defect $3 \mathrm{~cm}$ in diameter. There was a small dural tear about $1 \mathrm{~cm}$ from the sinus from which about $1 \mathrm{ml}$. of pulped brain was removed. The RA was estimated at a few seconds and the PTA about 30 minutes. On examination one day after injury speech was considered - to te normal and no permanent sensory-motor loss resulted from the injury. He has worked full-time since 1946 and is now a production control assistant.

Case no. 401 He was wounded in 1944 at the age of 24 by a missile which entered the left parieto-occipital region of the brain and crossed the midline to lodge $1.2 \mathrm{~cm}$ above the right petrous temporal bone. At operation, 30 hours after injury, blood clot, brain tissue, and bone fragments were removed from the wound and the ventricle was entered. Four days after injury it was 'impossible to test vision but he gropes about as if blind'. This resolved to leave him with a permanently impaired right homonymous field. He showed gross topographical memory loss and topographical disorientation, of which the residual symptoms are still in evidence. Initially, he had a global aphasia with jargon speech, a very severe nominal defect, and -aifficulty in reading. Seven months after injury his speech had improved considerably but he still had difficulty in reading and calculating; the latter defects have persisted but he can now understand written nacrative, although it takes him a long time to do so. He has been unemployed most of the time since his injiry and is still inclined to lose his way in the small county town in which he has lived all his life.

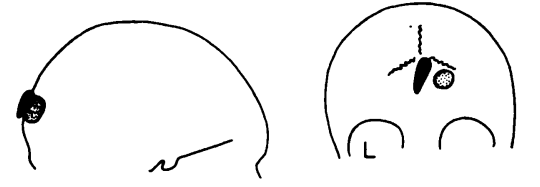

Case no. 461 This man was wounded in June 1944 at the age of 22 by a missile which penetrated the occipital region $2 \mathrm{~cm}$ to the left of the midline and $1 \mathrm{~cm}$ anterior to the lambdoid suture. Radiography showed a penetrating left occipital wound with bone chips indriven about $2.5 \mathrm{~cm}$ and a small metal fragment $1 \mathrm{~cm}$ to the right of the midline. At operation four days after injury four large and two small bone chips were removed from the entrance wound to a depth of 2.5 to $3 \mathrm{~cm}$. There was blood in the CSF which was thought to be due to the transventricular course of the metal fragment. Five days after injury he was confused and disorientated, and confabulating about his injury. Three weeks after injury he still showed a Korcakoff-like memory impairment, but during the following two months he improved considerably, although a mild impairment of memory has persisted. No sensory-motor loss was observed either during the acute or chronic phase and no dysphasic features were noted but he had a permanent right homonymous ri.mianopia. He now works as a coalman.

Case no. 103 He was wounded in 1944 at the age of 28 . He was blind immediately after injury and several hours later all vision was blurred, although the RA and PTA were probably a few seconds only. The scalp wound was debrided two days after injury. Eight days after injury he was unable to read anything except ñewspaper headlines but his spontaneous speech was normal. He had a transient right homonymous hemianopia and for a few months both fields were constricted; these subsequently cleared and were full on recent perimetric testing. During the acute phase, he had difficulty in finding his way about but this also cleared less than a month after injury. He was then able to read about six consecutive pages of book print. His reading improved gradually but he still finds it tiring to read for more than 15 minutes. He developed erilepsy with a visual aura but had not had any fits during the three years before his recent admission in 1965. He now works as a customs watcher in the docks.

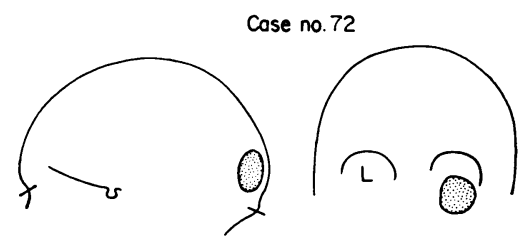

Case no. 152
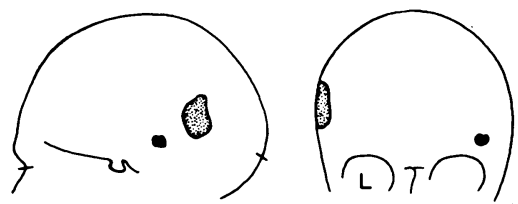

Cose no.40I
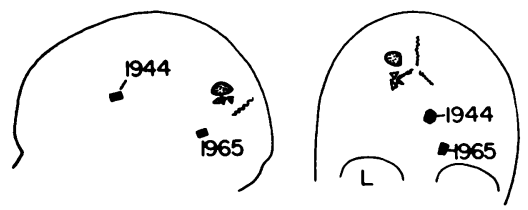

Case no. 461

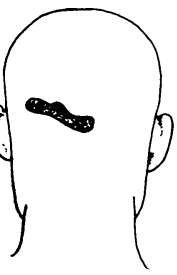

Case no. 103 
TABLE 4A

DISTRIBUTION OF ERRORS IN NAMING INDIVIDUAL PICTURES IN LH AND RH GROUPS

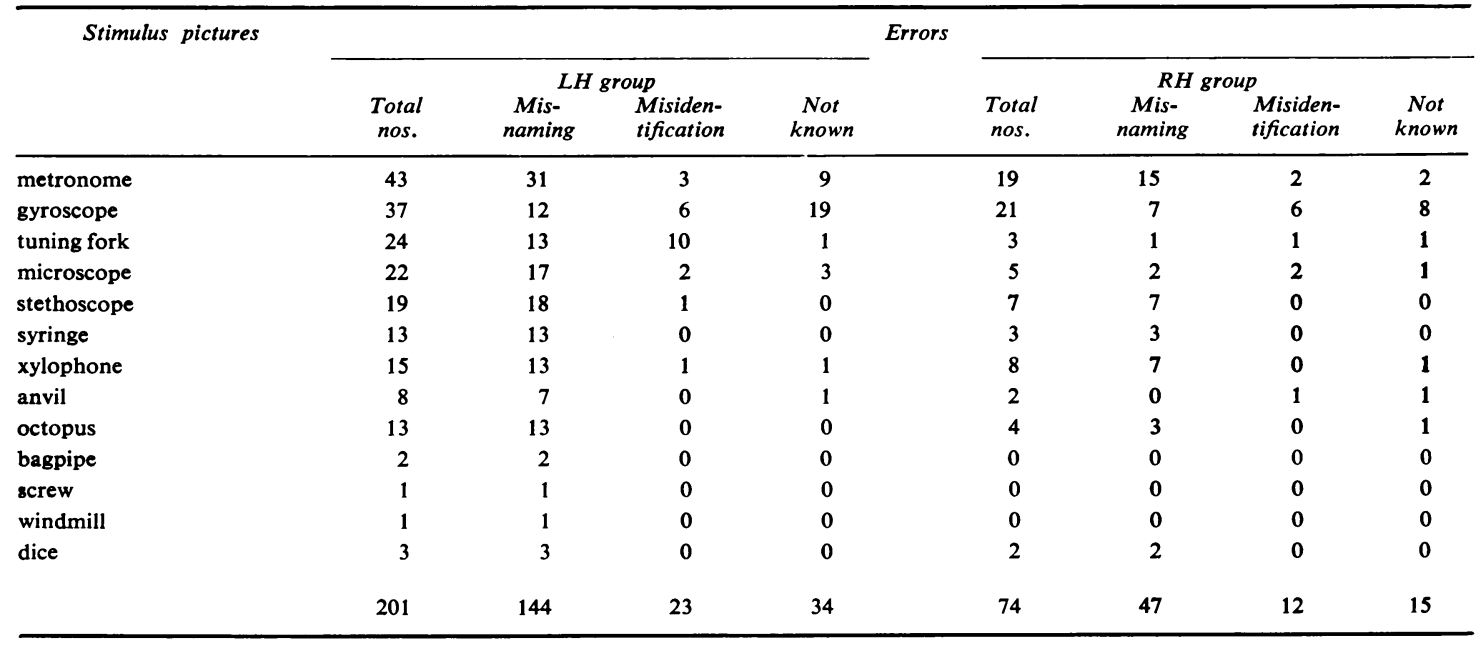

TABLE 4B

DISTRIBUTION OF ERRORS IN NAMING INDIVIDUAL PICTURES IN CONTROL AND BILATERAL GROUPS

\begin{tabular}{|c|c|c|c|c|c|c|c|c|c|}
\hline \multirow[t]{3}{*}{ Stimulus pictures } & \multicolumn{9}{|c|}{ Errors } \\
\hline & \multicolumn{4}{|c|}{ Control group I } & & \multicolumn{4}{|c|}{ Bilateral group } \\
\hline & $\begin{array}{c}\text { Total } \\
\text { nos. }\end{array}$ & $\begin{array}{c}\text { Mis- } \\
\text { naming }\end{array}$ & $\begin{array}{l}\text { Misiden- } \\
\text { tification }\end{array}$ & $\begin{array}{c}\text { Not } \\
\text { known }\end{array}$ & & $\begin{array}{l}\text { Total } \\
\text { nos. }\end{array}$ & $\begin{array}{c}\text { Mis- } \\
\text { naming }\end{array}$ & $\begin{array}{l}\text { Misiden- } \\
\text { tification }\end{array}$ & $\begin{array}{c}\text { Not } \\
\text { known }\end{array}$ \\
\hline metronome & 13 & 8 & 1 & 4 & & 25 & 15 & 4 & 6 \\
\hline gyroscope & 13 & 0 & 0 & 13 & & 24 & 4 & 8 & 12 \\
\hline tuning fork & 5 & 2 & 3 & $\mathbf{0}$ & & 19 & 9 & 9 & 1 \\
\hline microscope & 5 & 4 & 0 & 1 & & 13 & 6 & 6 & 1 \\
\hline xylophone & 3 & 3 & 0 & 0 & & 15 & 11 & 2 & 2 \\
\hline syringe & 3 & 3 & 0 & 0 & & 4 & 4 & $\mathbf{0}$ & $\mathbf{0}$ \\
\hline stethoscope & 2 & 2 & $\mathbf{0}$ & 0 & & 11 & 10 & 1 & 0 \\
\hline octopus & 2 & 1 & 0 & 1 & & 4 & 3 & 1 & 0 \\
\hline anvil & 1 & 1 & 0 & 0 & & 5 & 5 & 0 & 0 \\
\hline typewriter & 0 & 0 & 0 & 0 & & 1 & 1 & 0 & 0 \\
\hline \multirow[t]{2}{*}{ dice } & 0 & 0 & 0 & 0 & & 1 & 1 & 0 & 0 \\
\hline & 47 & 24 & 4 & 19 & & 122 & 69 & 31 & 22 \\
\hline
\end{tabular}

three or more errors of misidentification (see Table 3) and thus differed significantly in this respect. The clinical and anatomical features of these five subjects (group B), together with tracings of the lateral and anterior-posterior radiographs, ${ }^{1}$ are described in Fig. 5b. None of these men are dysphasic (although one was dysphasic during the acute phase) and it will be seen their lesions involved the occipital and posterior parietal region of the brain.

${ }^{1}$ These were not available for one subject (case no. 103) of whom the neurosurgeon's drawing of the entry wound has been shown. 


\section{DISCUSSION}

The difficulty in naming objects shown by the $\mathbf{L H}$ and bilateral groups was slight compared with the impairment of acute neurological patients whose scores in the task often fall well below the lowest score obtained by any member of our experimental sample; but it was significant statistically. In contrast, the RH group was unimpaired and indeed there has been no evidence from other language tasks that their performance can be distinguished from that of normal control subjects in the same age group. Thus, naming to confrontation, already described as the most useful test in previous studies of acute neurological patients with dysphasia (Weisenburg and McBride, 1935; Chesher, 1937) has proved a reasonably sensitive technique for measuring residual difficulties. It could also be used to study the deterioration or recovery of language function in acute pathology.

This experiment confirmed the relationship between response latency and word frequency in both control and experimental groups, and the implications of this finding for theories of word storage and retrieval have been explored elsewhere (Oldfield and Wingfield, 1965a; Oldfield, 1966; Wingfield, 1966, 1967, 1968). The latency graphs shown in Fig. 4 merit one or two comments. In the first place it will be seen that, within the particular conditions and technique of this experiment, no difference is to be found between right- and lefthemisphere subjects. There is thus an apparent discrepancy with the findings quoted by Oldfield (1966), as shown in Fig. 8 of that communication. The reason for this difference is that the earlier graphs were based on mean latencies calculated for all subjects, whereas those used in our Fig. 4 take into account only those subjects who responded correctly to all 20 items.

The latency differences between control and unilateral groups can not yet be interpreted. Such differences may reflect different limiting factorsverbal and perceptual-and certainly pose a problem which requires further experimental scrutiny. In this context, we note relevant experiments (Bisiach, 1966; Barton, Maruzewski, and Urrea, 1969) with modifications of the object-naming technique which were designed to examine verbal and visual-perceptual aspects of the task.

An interesting relationship exists, however, between the latencies for unilateral and bilateral lesions. Bilateral lesions sometimes produce disorders of function that are not merely the sum of those resulting from unilateral ones (see Teuber, 1964; Benton, 1968; Ratcliff, 1970) and so far as slowing of responses in the object-naming task is concerned this view would appear to be borne out by our present findings. If we designate the 'deficit' in this task by the difference, for each word-frequency, between the unilateral lesion patients and the control group as $\mathrm{U}$, and that for the bilateral groupsimilarly calculated-as B, then on a 'summative' view we might expect the slope of the regression of $B$ on $U$ to be about 2. Appropriate calculation shows that for our data this regression is linear $(F=44 \cdot 67$, $P<0.01$ ) and that the slope of the line is 3.2 . It would appear, then, that so far as the slowing of response is concerned, the general effect of bilateral lesions is greater than what might be expected from the sum of the unilateral lesion deficits.

Considering now the distinction between dysphasic and non-dysphasic performance, this was clear-cut in the unilateral LH group and thus suggested that nominal difficulties do not occur irrespective of the site of the lesion within the left hemisphere. Moreover, there was some indication of recovery from dysphasia over time, in that 12 of the 41 men originally diagnosed as dysphasic were no longer clinically diagnosed as such during their recent admission. Tests also confirmed that they were as efficient at the naming task-in terms of both the ability to name and speed of response-as subjects in the LH group who had never shown dysphasic features or normal control subjects. Either the criteria for diagnosis have changed or there has been a substantial improvement in this small group; and the testimony of the men themselves supports the latter interpretation.

In contrast, the distinction between dysphasic and non-dysphasic performance in the bilateral group was less obvious; and indeed-in terms of score alone-it was not possible to distinguish between these groups. This suggests that more than one limiting factor underlies the impairment shown by the bilateral group.

Failure in naming tasks can be found in other clinical conditions besides aphasia; it may result from disconnection syndromes or more generalized intellectual deterioration (Geschwind, 1967). In our groups, naming errors were clearly related to the language retrieval process, as evidenced by the paraphasic and mime responses made by subjects, and their recognition of the name when spoken. Naming errors predominated in the unilateral dysphasic group, and subjects with marked nominal difficulty in this task had lesions in the left temporoparietal area. This association, reported by Marie and Foix (1917) and Russell and Espir (1961) in gunshot-wound cases, has also been noted in patients with focal brain disease (Mills and McConnell, 1895; Henschen, 1925; Symonds, 1953; Brain, 1961 ; and Hécaen and Angelergues, 1965). Nominal 
difficulties have indeed been described as common in otitic abscesses extending through the tegmen tympani and invading the lower part of the temporal lobe (Kinnier Wilson, 1926).

We have recently observed a marked nominal defect, in speech and on this test (three out of 26 objects correctly named), in a 63 year old man whose spontaneous speech was relatively fluent. He used all parts of speech and many grammatical phrases but often failed to produce the noun subject or object. In this case, the diagnosis was hypertensive cerebrovascular disease, complicated by intracerebral haemorrhage and haematoma of the left temporal lobe. The only clinical abnormalities, apart from the dysphasia, were a slight right supranuclear facial weakness and a transient right homonymous hemianopia. There were no sensory, motor, or reflex abnormalities. The EEG showed prominent slow wave abnormalities over the left mid-temporal region. A radioactive brain scan showed an area of increased uptake in the left temporal area, and a left carotid angiogram demonstrated an avascular area in the left temporal lobe.

Turning now to those nine men in the LH group who showed significant, although residual, nominal deficits in the naming task, it will be seen that their lesions were in that temporo-parietal region within which small wounds have been found to cause severe disorganization in all aspects of speech function during the acute phase (Russell, 1961). The residual effects of this global disorganization were still evident in four of the nine men and their pattern of deficit was very similar to that described by Marie and Foix (1917) as the temporal-lobe syndrome. There was no evidence that size of lesion per se contributed to this defect but all except one of the subjects impaired on our criterion had deep lesions; and this factor of subcortical damage is probably important in determining the severity and persistence of language disorders (Head, 1926).

In contrast, there were individual dysphasic subjects, often with posterior frontal or central lesions and characteristic motor aphasia, who were not significantly impaired in this formal naming task, although word-finding difficulties were obvious in spontaneous conversation. It may be that for these subjects the presentation of the objectdrawing facilitates the retrieval of its name in a way reminiscent of Head's (1926) patient (case no. 2) who had gross naming and reading difficulties but could sometimes read an object name when the corresponding object was included in the test material in front of him.

There were also dysphasic subjects with high scores in the task-that is, scores above the median control score. One of these men with a posterior parieto-temporal lesion failed to recite the alphabet $\bar{Z}$ obtained significantly low scores in conventiona? word fluency tasks and complained of word-findinge difficulties when flustered. His family reported thaE his speech was at times unintelligible. The remain ing three men had parietal or fronto-parietals lesions; they complained of word-finding diffis culties and one of them noted difficulty in understanding verbal messages. Such evidence point $\vec{乛}$ to dissociations in language performance within the dysphasic group and thus supports the differential? concept of aphasia that has been cogently argued bye Bastian (1898), Kinnier Wilson (1926), Luria (1964음. 1970), and Weigl and Bierwisch (1970) among others $\frac{\text { ? }}{?}$

The misidentification errors which occurred migh well be regarded as a kind of paranopsia-the identification of the stimulus as another object sharing some of its visual characteristics-for example, TUNING FORK $\rightarrow$ magnet, ANVIL $\rightarrow \vec{\omega}$ shoemaker's last, GYROSCOPE $\rightarrow$ fan. The five subjects who tended to misidentify object-pictures had posterior lesions; none of them showed anye sensory-motor impairment or made errors in clinical tests of stereognosis. Their visual field defeets can hardly be regarded as a sufficient condition this misidentification, in that there were a num ger of other subjects with hemianopic field defects who did not make errors of this kind.

This tendency to misidentification may be a miles form of the visual object agnosia described $\$ y^{\circ}$ Lissauer (1890) who argued that this disorder $\overrightarrow{0}$ be satisfactorily demonstrated only in the absecer of speech disorder or general mental deterioration Our cases certainly meet these criteria but never $\frac{O}{\xi}$ theless present a very slight version of the disordee which is not clinically evident and can be detected only in certain experimental conditions. In this, io resembles the visual perceptual impairments so elegantly analysed by Poppelreuter (1917). Three o $\overrightarrow{\bar{p}}$ his patients with occipital gunshot-wounds had difficulty with simple line drawings but could recognize coloured and shaded pictures; and, as he. pointed out, the misrecognition errors of such patients were often visually similar to the stimulus for example, KETTLEDRUM $\rightarrow$ pot, LION and FOX $\rightarrow$ dog.

Certainly no cases of frank visual agnosia werê found in our experimental population, nor has the syndrome been reported as a lasting consequence of missile injury to the brain (Poppelreuter, 1917 Head, 1926; Teuber, Battersby, and Bender, 1960)으․ But Poppelreuter and subsequently Kinsbourno (1966) have shown a significant impairment of tachistoscopic thresholds for object recognition in veterans with occipital-lobe lesions; and the lattet suggested that minor, subclinical forms of visuab 
object-agnosia (recognition defect), which can be dissociated from impaired detection thresholds, are not infrequent.

Misrecognition of object-drawings in our experimental sample was associated with bilateral occipitallobe damage. Two of Poppelreuter's three cases (Henkel and Bittner) appear to have sustained bilateral occipital damage and the third (Schlottmann) had a left occipital entry wound, but there is no indication of the direction and extent of the missile track from the artist's drawing. The bilateral nature of lesions associated with agnosia has often been emphasized (Freud, 1891), and Nielsen (1946), reviewing the clinical literature. attributed visual object agnosia to a cortical lesion of the major second and third occipital convolutions or destruction of the connections from both calcarine areas to them.

The emphasis on bilateral lesions is a feature emerging not only from the study of misidentification errors but also from the results as a whole. The bilateral deficit can hardly be ascribed to the diffuse effects of especially severe lesions: there were other tasks in which the performance of the bilateral group was comparable with or even slightly better than that of the unilateral groups; and there were several men with large anterior bilateral lesions who showed no deficit in language and spatial tasks. And while the impairment of word retrieval shown by the bilateral group can be explained by a combination of identification and naming errors, the significantly increased response latency can not be so interpreted, since it refers only to those men who successfully responded to 20 of the test items. Perhaps further work will indicate whether this apparent slowing-up of response is a characteristic feature of men with bilateral or bilateral posterior lesions and whether it is specifically related to their performance in certain types of visual (and spatial) task.

In the meantime, the pattern of results lends support to the search for dissociations within groups of subjects with left hemisphere lesions. Not all dysphasic subjects-including those with motor dysphasia and those whose salient difficulties were in reading and writing-showed difficulty in this confrontation naming task. Dissociated deficits are sometimes concealed by group comparisons that are designed to study hemispheric asymmetry, and they are not easy to detect in groups of dysphasic patients as pure cases are always in the minority (Kinnier Wilson, 1926). The analysis of striking individual contrasts in performance (Symonds, 1953), however, may shed light on the processing of language by the brain.

We wish to thank Professor W. Ritchie Russell, both for the opportunity to study these cases and also for his constant advice in the investigation of this head injury series. We are also indebted to Professors O. L. Zangwill and Henri Hécaen for their valuable criticism of the draft paper.

\section{REFERENCES}

Alajouanine, T., Castaigne, P., Lhermitte, F., Escourolle, R., and Ribaucourt, B. de (1957). Étude de 43 cas d'aphasie post-traumatique. Encéphale, 46, 1-45.

Barton, M., Maruszewski, M., and Urrea, D. (1969). Variation of stimulus context and its effects on word-finding ability in aphasics. Cortex, 5, 351-365.

Bastian, H. C. (1898). A Treatise on Aphasia and Other Speech Defects. Lewis: London.

Benton, A. L. (1968). Differential behavioural effects in frontal lobe disease. Neuropsychologia, 6, 53-60.

Bisiach, E. (1966). Perceptual factors in the pathogenesis of anomia. Cortex, 2, 90-95.

Brain, W. R. (1961). Speech Disorders, Aphasia, Apraxia and Agnosia. Butterworth: London.

Broadbent, W. H. (1884). On a particular form of amnesia. Loss of nouns. Med-chir Trans., 67, 249-264.

Chesher, E. C. (1937). Aphasia. I. Technique of clinical examinations. Bull. Neurol. Inst., N.Y., 6, 134-144.

Freud, S. (1891). Zur Auffassung der Aphasien. F. Deutike, Leipzig. (English translation by E. Stengel On Aphasia. Imago: London, 1953).

Geschwind, N. (1967). The varieties of naming errors. Cortex, 3, 97-112.

Head, H. (1926). Aphasia and Kindred Disorders of Speech. Cambridge University Press: Cambridge.

Hécaen, H., and Angelergues, R. (1965). Pathologie du Langage. Larousse: Paris.

Henschen, S. E. (1925). Clinical and anatomical contributions on brain pathology. (Abstract and comments by W. F. Schaller.) Arch. Neurol. Psychiat. (Chicago), 13, 226-249.

Howes, D. (1964). Application of the word-frequency concept to aphasia. In Disorders of Language: Ciba Foundation Symposium, pp. 47-78. Edited by A. V. S. de Reuck and M. O'Connor. Churchill: London.

Kinnier Wilson, S. A. (1926). Aphasia. Kegan Paul, Trench, Trubner: London.

Kinsbourne, M. (1966). Visual Recognition Deficit following Focal Cerebral Injury. Paper read at 18th International Congress of Psychology, Moscow, 4-12 August.

Lissauer, H. (1890). Ein Fall von Seelenblindheit nebst einem Beitrag zur Theorie derselben. Arch. Psychiat. Nervenkr., 21, 222-270.

Lotmar, F. (1919). Zur Kenntnis der erschwerten Wortfindung und ihre Bedeutung für das Denken des Aphasischen. Schweiz. Archiv. Neurol. Psychiat., 5, 206-239; and 6, 3-36.

Luria, A. R. (1964). Factors and forms of aphasia. In Disorders of Language: Ciba Foundation Symposium, pp. 143-167. Edited by A. V. S. de Reuck and M. O'Connor. Churchill: London.

Luria, A. R. (1970). Traumatic Aphasia. Mouton: The Hague.

Marie, P., and Foix, C. (1917). Les aphasies de guerre. Rev. neurol., 24, 53-87.

Mills, C. K., and McConnell, J. W. (1895). The naming centre, with the report of a case indicating its location in the temporal lobe. J. nerv. ment. Dis., 22, 1-7.

Newcombe, F. (1969). Missile Wounds of the Brain: a Study of Psychological Deficits. Oxford University Press: London.

Newcombe, F., Oldfield, R. C., and Wingfield, A. (1965). Object-naming by dysphasic patients. Nature (Lond.), 207, 1217-1218. 
Nielsen, J. M. (1946). Agnosia, Apraxia, Aphasia. Their Value in Cerebral Localisation. 2nd ed. Hoeber: New York.

Oldfield, R. C. (1966). Things, words and the brain. Quart.J. exp. Psychol., 18, 340-353.

Oldfield, R. C., and Wingfield, A. (1965a). Response latencies in naming objects. Quart. J. exp. Psychol., 17, 273-281.

Oldfield, R. C., and Wingfield, A. (1965b). A Series of Pictures for Use in Object-Naming. M.R.C. Psycholinguistics Research Unit Special Report No. PLU/65/19.

Poppelreuter, W. A. (1917). Die psychischen Schädigungen durch Kopfschuss im Kriege 1914/16: Bd. 1. Die Störungen der niederen und höheren Sehleistungen durch Verletzungen des Okzipitalhirns. Voss: Leipzig.

Ratcliff, G. G. (1970). Aspects of Disordered Space Perception. D. Phil. thesis, Oxford University.

Rochford, G., and Williams, M. (1965). Studies in the development and breakdown of the use of names. Part IV. The effects of word frequency. J. Neurol. Neurosurg. Psychiat., 28, 407-413.

Russell, W. R. (1961). Anatomical aspects of aphasia. Scottish med. J., 6, 237-254.

Russell, W. R., and Espir, M. L. E. (1961). Traumatic Aphasia. Oxford University Press: London.

Russell, W. R., and Young, R. R. (1969). Missile wounds of the parasagittal Rolandic area. In Modern Neurology, pp. 289-302. Edited by S. Locke. Little, Brown: Boston.

Schiller, F. (1947). Aphasia studied in patients with missile wounds. J. Neurol. Neurosurg. Psychiat., 10, 183-197.
Symonds, Sir C. (1953). Aphasia. J. Neurol. Neurosurg Psychiat., 16, 1-6.

Teuber, H. L. (1964). The riddle of frontal lobe function in man. In The Frontal Granular Cortex and Behaviour, pp.O 410-444. Edited by J. M. Warren and K. Akert. McGrawHill: New York.

Teuber, H. L., Battersby, W. S., and Bender, M. B. (1960).ర Visual Field Defects After Penetrating Missile Wounds of the Brain. Harvard University Press: Cambridge, Mass.

Thorndike, E. L., and Lorge, I. (1944). The Teacher's Word Book of 30,000 Words. Bureau of Publications, Teacher's College, Columbia University, New York.

Weigl, E., and Bierwisch, M. (1970). Neuropsychology and $\overrightarrow{\bar{A}}$ linguistics: topics of common research. Foundations of Language, 6, 1-18.

Weisenburg, T. H., and McBride, K. E. (1935). Aphasia: $A$ Clinical and Psychological Study. Commonwealth Fund $\frac{\bar{s}}{\bar{D}}$ New York.

Wepman, J. M., Bock, R. D., Jones, L. V., and Van Pelt, D. ำ (1956). Psycholinguistic study of aphasia: a revision of the concept of anomia. J. speech Dis., 21, 468-477.

Wingfield, A. (1966). The Identification and Naming of Objects. Unpublished D.Phil. thesis, Oxford University.

Wingfield, A. (1967). Perceptual and response hierarchies in object identification. Acta Psychologica, 26, 216-226.

Wingfield, A. (1968). Effects of frequency on identification and naming of objects. Amer.J. Psychol., 81, 226-234. 